\title{
The mortal cause of sudden ECG changes in patients with chronic aortic insufficiency: Aortic dissection
}

\author{
MAHMUT YESIN ${ }^{1, *}$, TURGUT KARABAĞ ${ }^{2}$, MACIT KALÇIK $^{3}$, SÜLEYMAN KARAKOYUN ${ }^{4}$, \\ METIN ÇAĞDAŞ ${ }^{4}$, ZAUR İBRAHIMOV ${ }^{5}$ \\ ${ }^{1}$ Department of Cardiology, Kars Harakani State Hospital, Kars, Turkey \\ ${ }^{2}$ Department of Cardiology, Istanbul Training and Research Hospital, Istanbul, Turkey \\ ${ }^{3}$ Department of Cardiology, Hitit University Corum Training and Research Hospital, Corum, Turkey \\ ${ }^{4}$ Department of Cardiology, Faculty of Medicine, Kars Kafkas University, Kars, Turkey \\ ${ }^{5}$ Department of Emergency Medicine, Kars Harakani State Hospital, Kars, Turkey \\ *Corresponding author: Mahmut Yesin, MD; Ismail Aytemiz Bulvari, Yeni Devlet Hastanesi, Kars 36000, Turkey; Phone: +90 5324726596 ; \\ Fax: +90 4742125671 ; E-mail: mahmutyesin@yahoo.com
}

(Received: January 26, 2017; Revised manuscript received: March 24, 2018; Second revised manuscript received: June 11, 2018; Accepted: November 30, 2018)

\begin{abstract}
The symptoms of aortic dissection (AD) may be highly variable and may mimic other much common conditions. Thus, a high index of suspicion should be maintaned, especially when the risk factors for AD are present or signs and symptoms suggest this possibility. However, sometimes AD may be asymptomatic or progression may be subclinical. Various electrocardiographical (ECG) changes may be seen in AD patients such as ST segment elevation in aVR as well as ST segment depression and T-wave inversion. In this case report, we reported a patient with acute AD whose ECG revealed ST segment elevation in aVR lead in addition to diffuse ST segment depression in other leads.
\end{abstract}

Keywords: aorta, aortic dissection, electrocardiography, transthoracic echocardiography, ST segment elevation

\section{Case Presentation}

A 68 -year-old man who had a history of aortic insufficiency and ascending aort dilatation for 5 years was admitted to our emergency department with exertional dyspnea and coughing. He had no history of hypertension or diabetes mellitus. The physical examination revealed a blood pressure of $100 / 50 \mathrm{mmHg}$ and a heart rate of 80 beats /min. His body temperature was normal. Blood pressure values were similar between the right and left arms. Femoral, tibialis posterior, and dorsalis pedis pulses were palpable and similar between the right and left limbs. A $3 / 6$ diastolic decrescendo murmur was heard along the left sternal border. Electrocardiography (ECG) showed normal sinus rhythm without any ST segment or T-wave changes. Increased cardiothoracic index and prominent aortic arch were observed on chest $\mathrm{X}$-ray examination (Fig. Ia). While awaiting the results of laboratory tests, patient described severe chest pain. A repeated ECG showed ST segment elevation in aVR lead and diffuse ST segment depressions in all other derivations (Fig. 16). His blood pressure was $90 / 50 \mathrm{mmHg}$ and heart rate was 100 beats/min. Transthoracic echocardiography revealed severe aortic regurgitation, dilated ascending aorta with a diameter of $5.27 \mathrm{~cm}$, and intimal dissection flap that was prolapsing into the left ventricle during diastole (Fig. $I c$ and $l d$ ). Left ventricular ejection fraction was found within the normal limits. Immediate surgery was suggested for the patient just before a sudden cardiopulmonary arrest. Cardiopulmonary resuscitation was performed; however, patient passed away.

This is an open-access article distributed under the terms of the Creative Commons Attribution-NonCommercial 4.0 International License, which permits unrestricted use, distribution, and reproduction in any medium for non-commercial purposes, provided the original author and source are credited, a link to the CC License is provided, and changes - if any - are indicated. 
(a)

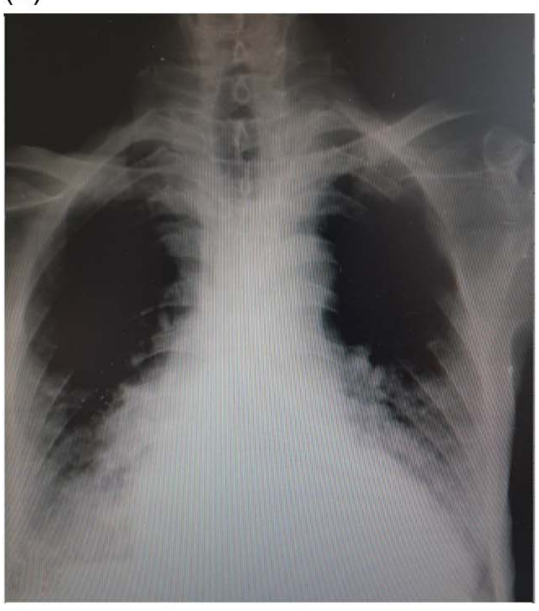

(c)

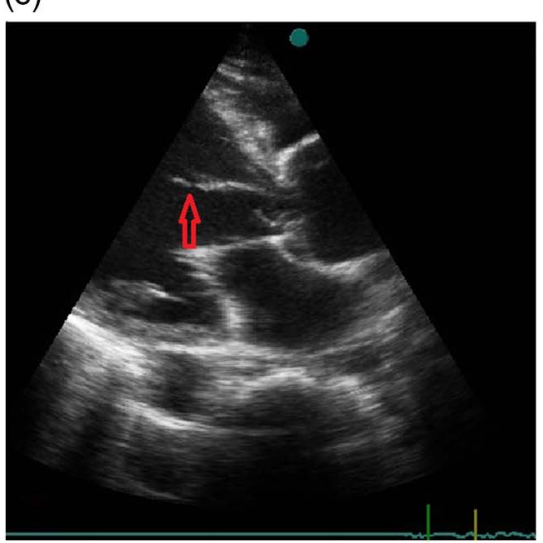

(b)

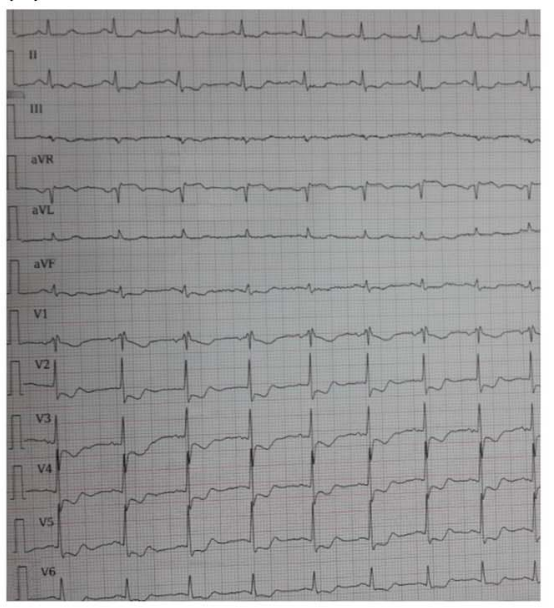

(d)

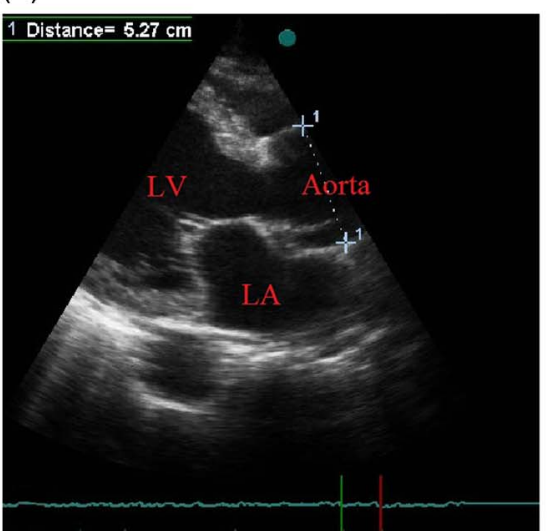

Fig. 1. Chest X-ray examination showed an increased cardiothoracic index and prominent aortic arch (a). A repeated electrocardiography showed ST segment elevation in aVR lead and diffuse ST segment depressions in all other derivations (b). Transthoracic echocardiography revealed an intimal dissection flap that prolapsed into the left ventricle during diastole (c) and a dilated ascending aorta with a diameter of $5.27 \mathrm{~cm}(\mathrm{~d})$

\section{Discussion}

The vast majority of patients with acute AD commonly have sudden and severe chest, back, or abdominal pain, which is usually maximal at its onset. Although most patients with type-B AD are hypertensive, several patients with type-A AD are normotensive or hypotensive on admission [1]. The present patient was normotensive on admission; however, his hemodynamic status was deteriorated in a short time period.

The ECG changes in $\mathrm{AD}$ are usually non-specific; however, approximately $1 \%-2 \%$ of the patients have acute ST segment elevation [2]. In a study conducted by Hirata et al. [3], ECG changes were investigated in patients with acute $\mathrm{AD}$. They reported that the most common ECG changes in patients with acute AD were ST segment depression or T-wave changes. They also reported more common cardiogenic shock and cardiac tamponade in patients with ST depression or T-wave changes. The prevalence of ST segment elevation was reported to be $8.2 \%$ in patients with acute type-A $\mathrm{AD}$ [3]. Although ST segment elevation in aVR lead is not a common ECG sign in patients with acute $\mathrm{AD}$, diffuse ST segment depression with ST segment elevation in aVR lead was appeared just after the beginning of severe chest pain in the present patient. In such patients, ST segment elevation in aVR lead may reflect the occlusion of left main coronary artery orifice.

\section{Conclusions}

Acute $\mathrm{AD}$ is an emergency situation and immediate intervention should be performed. In patients with a history of aortic insufficiency and/or enlargement of ascending aorta when admitted to the emergency departments with sudden chest pain, acute AD should be considered in the differential diagnosis. The ECG 
changes such as diffuse ST segment depression with ST segment elevation in aVR lead may be a sign of not only coronary artery disease but also acute AD.

$$
\star * *
$$

Funding sources: None.

Data sharing: No additional data.

Authors' contribution: All the authors contributed in planning, conducting, and reporting of the work. All contributors are responsible for the overall content as guarantors.

Conflict of interest: All the authors have no conflict of interest.

\section{References}

1. Hagan PG, Nienaber CA, Isselbacher EM, Bruckman D, Karavite DJ, Russman PL, Evangelista A, Fattori R, Suzuki T, Oh JK, Moore AG, Malouf JF, Pape LA, Gaca C, Sechtem U, Lenferink S, Deutsch HJ, Diedrichs H, Marcos y Robles J, Llovet A, Gilon D, Das SK, Armstrong WF, Deeb GM, Eagle KA: International Registry of Acute Aortic Dissection (IRAD): New insights from an old disease. JAMA 283, 897-903 (2000)

2. Braverman AC: Acute aortic dissection: Clinician update. Circulation $122,184-188$ (2010)

3. Hirata K, Wake M, Kyushima M, Takahashi T, Nakazato J, Mototake $\mathrm{H}$, Tengan $\mathrm{T}$, Yasumoto $\mathrm{H}$, Henzan $\mathrm{E}$, Maeshiro $\mathrm{M}$, Asato $\mathrm{H}$ : Electrocardiographic changes in patients with type A acute aortic dissection. Incidence, patterns and underlying mechanisms in 159 cases. J Cardiol 56, 147-53 (2010) 